\title{
BLADE RUNNER: O HUMANO NA ÉPOCA DE SUA REPRODUTIBILIDADE TÉCNICA
} Blade Runner: the human in the age of its technical reproducibility Rafael Afonso da Silva*

\section{Resumo}

O propósito do presente ensaio é interpretar o filme Blade Runner, enfatizando as conexões entre tecnologia, relações sociais, experiência, memória e personalidade no mundo imaginário do filme. É um estudo feito na esteira de textos e conceitos benjaminianos. A versão do filme utilizada é a versão intitulada Blade Runner. Director's Cut. Método de trabalho: emersão, imersão, interrupção, isolamento, pôr legendas, montagem.

Palavras-chave: Tecnologia. Cinema

\section{Abstract}

The aim of this study is to interpret the movie Blade Runner, emphasizing the connections between technology, social relations, experience, memory and personality in the movie's imaginary world. This study is made in the wake of Benjamin's works and concepts. The used version of movie is Blade Runner: Director's Cut. Method of work: emersion, immersion, interruption, isolation, make subtitles, montage.

Keywords: Technology. Cinema.

* Mestre em Sociologia pela Universidade Estadual de Campinas (Unicamp). Email: : limacamarada@ hotmail.com. 
Tes yeux, illuminés ainsi que des boutiques

Et des ifs flamboyants dans les fêtes publiques,

sent insolemment d'un pouvoir emprunté.

(Baudelaire)

\section{IMAGENS NO FUNDO DO OLHO}

A primeira cena de Blade Runner descortina uma paisagem onde explosões industriais, como um instantâneo, se acendem e se apagam contra o céu cinzento da cidade, revelada menos por seus edifícios do que por uma miríade de pingos luminosos. Na seqüência, somos levados a contemplar novamente essas imagens, mas agora elas se revelam por um outro prisma, refletidas na distância sem fundo de um olho, o olho de Leon.

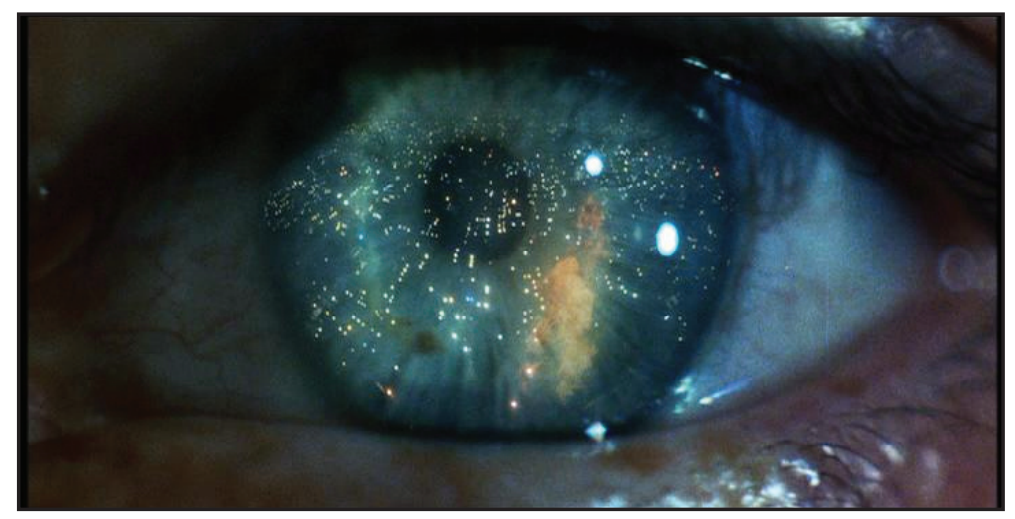

Banhadas pela umidade cromática do olho de Leon, essas imagens são transfiguradas, envolvidas em uma atmosfera fantasmal. Distendidas por sintetizadores eletrônicos, as notas diluídas, flácidas, da música de fundo reforçam esse efeito de dissolução aquosa na infinitude intensiva da cor. Flutuando nessa fantasia aquoso-cromática, essas imagens parecem inacessíveis, como aparições no fundo de uma infinita distância. São assim ilusoriamente investidas das características que Benjamin atribui ao fenômeno da aura: 
É uma figura singular, composta de elementos espaciais e temporais: a aparição irrepetível de uma distância, por mais perto que ela esteja. (BENJAMIN, 1987: 101)

\section{A imagem do olho no olho aparelho}

Dentro da Tirell Corporation, Leon é submetido a um teste para a detecção de replicantes. Ali ele se expõe, a contragosto, não somente para o indivíduo que aplica o teste, mas para um aparelho. A relação face-a-face cede lugar a uma relação mediada pelo aparelho. O olho de Leon é capturado por uma tela disposta entre ele e o controlador do teste. Ao lado da tela, um mostrador registra dilatações e contrações da íris. Nessa aparição, o olho perde sua substância, é privado de sua vida, da capacidade de olhar. Não é mais o fundo insondável em que uma imagem é afastada infinitamente do observador, mas uma imagem na superfície plana de uma tela, onde será dissecado por um bisturi muito mais penetrante que o instrumento médico que leva esse nome: o olho do aparelho.

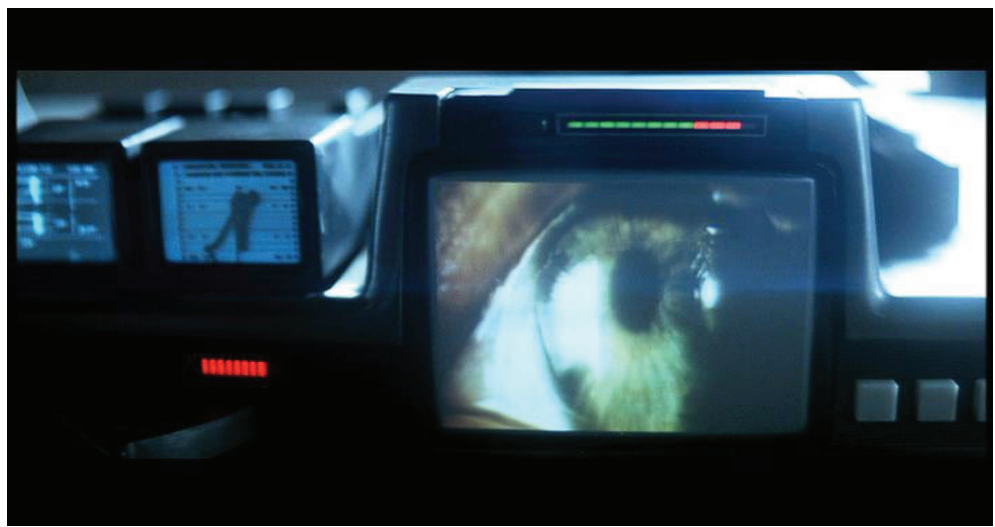

Ao escoar para o aparelho, ao transformar-se numa imagem clinicamente captada com a intenção explícita de expor seus micromovimentos, suas microdimensões, dissecado, penetrado pelo aparelho, o olho já não tem nenhuma profundidade, já não é capaz de envolver nenhum objeto numa atmosfera aurática, antes é envolvido, absorvido pelo aparelho. E 
essa absorção do olho pelo aparelho é apenas o indício da outra forma, muito mais envolvente, pela qual o mecanismo social e técnico se apossa dele.

\section{Propaganda: a mercadoria no nível do olho}

Em uma tela gigantesca acoplada na parede de um edifício, a palavra "Enjoy" surge luminosa na tela sob um fundo vermelho e é sucedida por outras igualmente dispostas sob um fundo vermelho: "Enjoy coca-cola". A palavra "enjoy", em sua aparição isolada, envolve todas as significações agrupadas em torno da palavra: satisfação, prazer, gozo, diversão, etc. A frase seguinte é uma frase imperativa que ordena ou aconselha a desfrutar/ enjoy de um objeto específico, coca-cola. A segunda frase, se aparecesse sozinha, mobilizaria com "enjoy" apenas as qualidades específicas que um indivíduo já desfrutou no consumo daquele objeto específico. Mas a sucessão das frases e a permanência do fundo vermelho criam uma afinidade secreta entre a mercadoria coca-cola e todas as significações agrupadas em torno da palavra "enjoy", em suas múltiplas associações com todos os objetos do mundo, real e imaginário, que um indivíduo possa, por sua experiência, relacionar com a palavra. No gesto distraído de olhar para cima, de repente, o indivíduo encontra
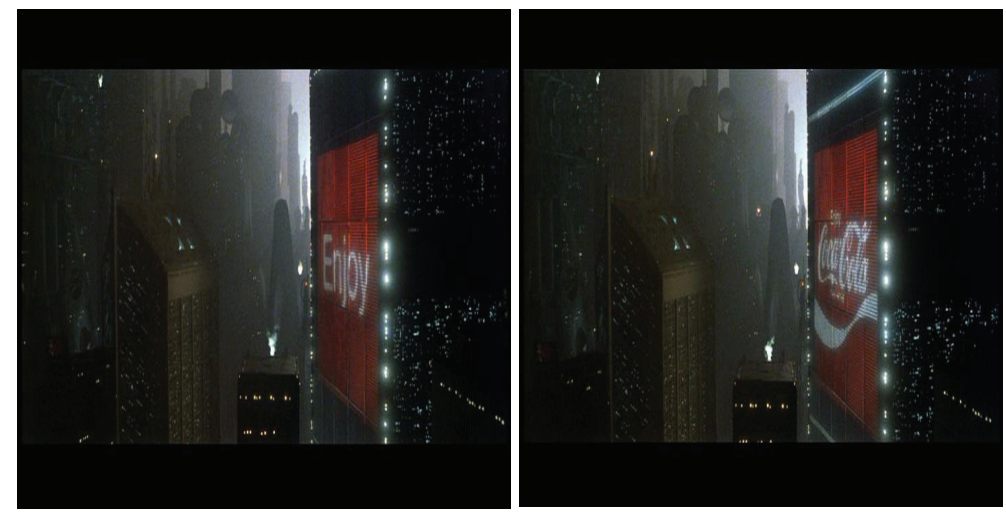

- a promessa do paraíso. 
O céu da cidade fictícia de Blade Runner, Los Angeles no ano de 2019, é saturado pela fantasmagoria da propaganda. Na propaganda, as mercadorias entram em conexões fantásticas, independentes de seu valor de uso. Em seu artifício, o mesmo objeto pode sempre receber novas significações. Tendo recebido essa significação, pode ser privado dela a qualquer momento e receber uma outra, ao ser arrastado para uma nova combinação arbitrária de significantes. A arte da propaganda assemelhase à arte do alegorista, desvendada por Benjamin na origem do drama barroco alemão (1984). Essa semelhança foi apontada por Benjamin em escritos posteriores. $\mathrm{O}$ alegorista arranca fragmentos de seus contextos e os dispõe um ao lado do outro, ora em uma combinação, ora em outra, para ver como se ajustam: aquela significação para esta figura, aquela figura para esta significação. A propaganda compartilha com o alegorista esse gesto autoritário de impor significações através da arte combinatória. Mas a intenção alegórica é diferente da intenção da propaganda.

$\mathrm{Na}$ alegoria, as coisas são depreciadas, humilhadas, arrancadas de seu contexto, para entrar na pátria alegórica como fragmento de um edifício que é síntese de conjunção e dispersão, que exibe o caráter fragmentário e, portanto, arbitrário de sua organização como imitação de seu conteúdo, a história, em tudo aquilo que ela tem de arbitrário na organização dos homens e das coisas. A alegoria afirma a vulnerabilidade do presente como fragilidade ao confessar o caráter construtivista da "nova lei" sob a qual os múltiplos fragmentos são reunidos.

Na propaganda, são outras as regras do jogo. O fetiche-mercadoria reduz o objeto à condição de mero significante da equivalência abstrata, de um traço abstrato (tempo de trabalho) que se repete em cada mercadoria como sempre-igual, Immergleich, para usar a expressão benjaminiana. No terreno da reprodutibilidade técnica, da produção em massa, a figura do sempre-igual aparece não apenas como um traço abstrato: sua ilusão adquire a aparência da materialidade na superabundância de produtos que aparecem como simples réplicas sem nenhum original. As coisas, depreciadas, humilhadas, arrancadas de seu contexto pelo fetichemercadoria e pela produção em massa, são assimiladas nessa condição pela propaganda não para expressar essa desvalorização sistemática dos 
objetos no mundo mercantil, mas para ocultá-la. O objetivo da propaganda é apresentar o indiferenciado na forma do diferenciado, o idêntico na forma do único. Ela não pode mais confessar o abismo entre a materialidade do objeto e a significação, deve ocultá-lo no próprio artifício. Só assim ela realiza sua mágica: extrair o novo do sempre-igual. A propaganda interrompe o fluxo do mundo para renovar o mundo para dentro, através do abraço excêntrico da significação. Ela é transfiguração. A propaganda nega a vulnerabilidade do presente ao transformar a contingência em presente “áurico”, monumental.

O efeito visado na propaganda é, sobretudo, ótico. Esse alvo é ditado pela preponderância da visão sobre a audição no mundo contemporâneo. No coração ruidoso das grandes cidades, é mais fácil apelar para os olhos do que para os ouvidos. A desvalorização da audição em prol de uma vinculação eminentemente ótica com o universo é, além disso, reforçada pelos ambientes públicos e, particularmente, pelo transporte coletivo, na qual pessoas são constrangidas a se olharem por um tempo mais ou menos longo sem se dirigirem a palavra. A propaganda somente faz obedecer a essa transformação na relação entre os sentidos humanos. O escopo da propaganda é colocar a mercadoria no nível do olho dos consumidores, não para irradiar as qualidades intrínsecas de seu material, mas a significação imposta pela arte de combinar imagens através da técnica da reprodução e da montagem. Mas nem a mercadoria, nem as imagens são valores de uso para o observador nessa aparição. O reverso do gesto autoritário da propaganda de impor significações através da combinação arbitrária de significantes é a curiosidade passiva de quem vê sem poder tocar em nada, sem poder alterar a "lei" que rege a organização das imagens produzidas pela intervenção tecnológica, "lei” decidida à sua revelia, assim como o preço da mercadoria numa etiqueta, assim como a "lei" (capital) que rege a configuração do mundo empírico. Blade Runner capta muito bem essa dimensão da propaganda. No filme, as imagens da propaganda pairam iridescentes muito acima das cabeças dos passantes, em dirigíveis ou suspensas nas paredes de edifícios gigantescos. Mas elas estão no nível do olho. É assim que elas se apossam dele. 


\section{O olho e a memória}

Deckard olha a fotografia de Rachael com a mãe. Subitamente a efêmera imagem fixada no instantâneo é reanimada. A sombra de um galho projetada sobre os rostos estremece. Os rostos adquirem vida. Deckard ouve vozes de crianças ecoando remotas. É uma constelação mnemônica que envolve a fotografia num fenômeno aurático. Mas há algo de perturbador nisso. Rachael não tem uma mãe: tem um incept date. E os conteúdos mnemônicos de Deckard são "implantes".

A ficção sugere uma situação-limite em que a memória pode ser replicada, como qualquer imagem na era da reprodutibilidade técnica, e "implantada" na mente desses seres humanos geneticamente programados chamados replicantes. O filme não diz como isso é possível. No roteiro de Hampton Fancher e David Peoples, Tyrell explica: "No caso de Rachael, eu simplesmente copiei e regenerei células do cérebro de minha sobrinha de dezesseis anos. Rachael se lembra do que minha pequena sobrinha se lembra." Diante dessa terrificante explicação de Tyrell, Deckard não consegue segurar um comentário irônico: "Eu vi um velho filme uma vez. O cara tinha parafusos em sua cabeça."

No final do filme, descobrimos que Deckard é um replicante porque o policial Gaff deixa um origami de um unicórnio para Deckard no caminho de sua fuga. O unicórnio é a imagem supostamente individual e secreta que povoa os sonhos de Deckard. O origami do unicórnio é uma legenda que diz a Deckard que as forças da ordem conhecem seus pensamentos. O unicórnio não é uma imagem de sonho criada para escapar à censura do superego e das instâncias conscientes de controle do ego, mas uma imagem "implantada" na cabeça de Deckard em benefício do "superego" real, das forças da ordem, que querem eternizar o presente, confirmando o padrão existente de "experiência". Tyrell, em sua conversa com Deckard, não tem nenhum pudor em dizer que o "implante" da memória nos replicantes é um modo de prevenir essa "estranha obsessão" dos replicantes de não reconhecer "as experiências que você e eu aceitamos como verdadeiras [granted]": "Depois de tudo, eles são emocionalmente inexperientes, com apenas uns poucos anos para armazenar as experiências que você e eu aceitamos como verdadeiras. Se nós lhes damos um passado, nós criamos 
um colchão ou um travesseiro para suas emoções e nós podemos controlálos melhor."

Tyrell é uma personalidade serena. É preciso lembrar que, além de ser o chefe do poderoso império corporativo que controla o processo de produção dos replicantes, a Tyrell Corporation, ele mesmo projeta 0 cérebro dos replicantes. Sua serenidade é a serenidade satânica de um estado de espírito que expressa a auto-suficiência imaginária de uma ciência que "deixou de se ocupar com o futuro das forças produtivas" liberadas por seu próprio saber (BENJAMIN, 1994: 157), assim como o Dr. Frankenstein abandona sua criatura na conhecida história a que Deckard se refere no comentário acima reproduzido. $O$ interior monumental da casa de Tyrell é a expressão do gigantismo narcisista de uma ciência que não reconhece nenhuma barreira de ordem moral ou material. Esse interior repele completamente o exterior. Não somente o indivíduo se recolhe dentro dele, mas, em sua monumentalidade, o próprio interior se recolhe completamente em si mesmo. É expressão da ilusão de uma ciência que se concebe separada dos nexos da vida, que trata de variáveis em condições artificialmente produzidas para afastar o acaso, que acredita poder "interromper o curso do mundo".

Interromper o curso do mundo - esse era desejo mais profundo de Baudelaire. O desejo de Josué. (BENJAMIN, 1994: 160)

Josué é aquele personagem bíblico que ordena que o sol deixe de girar para que ele vença o inimigo antes de o sol se pôr. É a manifestação máxima da vontade de reduzir todas as ordens de seres ao próprio desígnio. Tyrell, representante alegórico do poder da ciência e da tecnologia de penetrar e reconfigurar todo o mundo das coisas, inclusive a physis humana, é uma espécie de Josué profano. É muito sugestiva a cena em que ele aciona um mecanismo que escurece o vidro da janela panorâmica da sala. A intenção explicitada no roteiro é, através de um "polaroid effect", dar a impressão de que Tyrell tem o poder de apagar o sol.

No filme, a explicação de Tyrell sobre a técnica de "implante" da memória é suprimida, assim como o comentário de Deckard, talvez porque a 


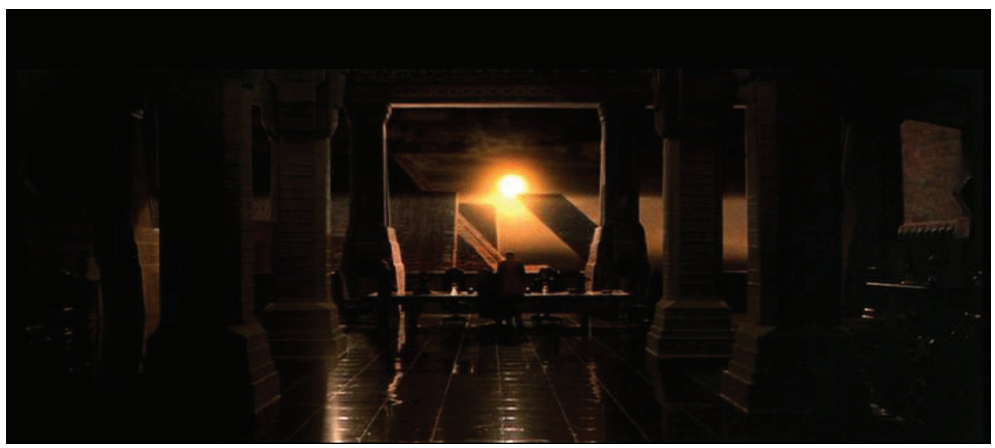

omissão torne mais verossímil a ficção do que uma explicação que poderia ser desancada por especialistas ou gerar polêmicas desnecessárias. Mas a explicação é irrelevante. O que importa é que a situação-limite evidencia uma mudança na matéria da "memória" na era da reprodutibilidade técnica.

Benjamin, em diversos textos, expôs o fato de que a reprodutibilidade técnica das imagens destrói a unicidade espacial-temporal dos eventos, aniquila o encantamento da distância, que caracteriza o fenômeno da aura, fazendo as coisas ficarem mais próximas na imagem, ou melhor, na sua reprodução. A reprodutibilidade técnica emancipa a imagem das limitações espaciais e temporais do objeto em sua existência única, tornando-a capaz de criar "experiência” (não no sentido da Erfahrung benjaminiana) em escala de massa. Na era da reprodutibilidade técnica e da manipulação das imagens, a imagem não é apenas produto, mas meio de produção: ela é uma técnica de organização da "experiência”.

Não parece mais admissível concordar com a noção kantiana da formatividade puramente subjetiva da objetividade, noção que pressupõe tanto a carência de integralidade de forma da objetividade como a existência de categorias universais que antecipam e governam a organização, pela compreensão (ativa), dos fenômenos captados pela intuição (passiva). Para nos ajudar na crítica dessa noção, é interessante citar aqui um fragmento de Sobre a percepção em si, um ensaio não concluído redigido por Benjamin em 1917:

Percepção é ler

Apenas o que aparece na superfície é legível 
Superfície que é configuração - continuidade absoluta

Esse fragmento afirma que: (1) a percepção não é somente receptividade ou passividade, como supõe a filosofia crítica, mas "leitura" de aparências; (2) o que se "lê" na percepção é apenas o que aparece na "superfície"; (3) a "superfície" é um conjunto de aparências que estão, elas mesmas, organizadas em um contexto, quer dizer, as aparências são contextuais, não fenômenos isolados postos em relação somente pela atividade a posteriori da compreensão. Mas esse fragmento precisa ser lido também na ordem inversa. Aliás, a própria inversão é demonstração de sua tese.

Superfície é configuração - continuidade absoluta

Apenas o que aparece na superfície é legível Percepção é ler

Nessa reordenação, o que o fragmento diz é: (1) as aparências são con-textuais, quer dizer, as aparências estão organizadas em uma "superfície" que é criada pela própria disposição das aparências, por sua con-figuração; (2) essa "superfície" conforma a "legibilidade" das aparências, os modos de percepção; (3) perceber é a atividade de "ler" o que essa "superfície" torna "legível". A percepção não é puramente receptividade, mas também não é pura volição, pois é uma atividade de "leitura" que se exerce no limite determinado pela "legibilidade" da objetividade, organizada em sua "superfície", na aparência, como "configuração". A noção de percepção como "leitura" não é a atribuição à percepção da capacidade performativa da compreensão kantiana: não é a "leitura" perceptiva que determina a disposição dos fenômenos, mas a disposição dos fenômenos na "continuidade absoluta" da "superfície", a con-figuração, que determina a "legibilidade", os modos possíveis de percepção dos eventos.

A tese desse fragmento torna-se mais compreensível quando pensamos na propaganda, tal como analisada acima. Na propaganda, a imagem de um objeto é um significante que recebe uma significação arbitrária de acordo com a sua disposição em relação a outras imagens-significantes numa "superfície", "superfície" que é montagem. É uma alteração da "forma objetiva" do objeto sem alteração de sua materialidade, de seu valor de uso efetivo. A propaganda simplesmente manipula a inscrição da imagem do 
objeto em uma "superfície", cuja configuração é concebida para manipular a "legibilidade" das imagens, os modos de "leitura", de percepção, do objeto. O que a propaganda vende é o valor que surge nessa inscrição do objeto numa "superfície" montada e rigorosamente controlada, não o valor de uso efetivo da mercadoria.

O que a propaganda evidencia é que a tecnologia da reprodução da imagem converte a própria imagem em uma tecnologia para organizar a "experiência". A imagem é a tecnologia voltada para o controle da configuração da "superfície" (locus, real ou virtual, de exponibilidade das aparências) e, portanto, da "legibilidade". Um plano atuante de composição intervém no controle da "legibilidade", através da montagem, da manipulação da inscrição das imagens na "superfície", antes que a percepção intervenha na composição perceptiva do evento através da "leitura". É um poder assustador. Aquele que tem o poder de determinar o plano atuante de composição da "superfície" tem o poder - de apagar o sol.

A situação-limite ficcional do "implante" da memória em Blade Runner é uma parábola. A realidade visada pelo filme é a outra, nãoficcional, da imagem como técnica. Essa realidade é revelada mais pelo cenário do que pela a trama. Contudo, é no diálogo entre cenário e trama que os dilemas da ficção se mostram como não-ficcionais e o cenário é tematizado, deixando de ser mero pano de fundo para explicitar o problema desconcertante da "memória" na era da reprodutibilidade técnica, ou melhor, na era da replicação generalizada.

Ao percorrer os espaços labirínticos de Los Angeles, somos a todo instante, em cada curva, assediados por imagens produzidas pela indústria publicitária. Rostos femininos com traços orientais anunciam produtos diversos, cujo caráter mercantil a propaganda pretende ofuscar sob o encanto desses rostos sorridentes e sensuais.

Em um dirigível, circula um anúncio que proclama uma "nova vida" nas colônias extraterrestres (off world), "uma chance de começar de novo". O anúncio é patrocinado pela Shimago-Dominguez Corporation, que se promove como uma empresa que está "ajudando a América a entrar no Novo Mundo [New World]". O filme denuncia aqui a verdadeira assinatura 


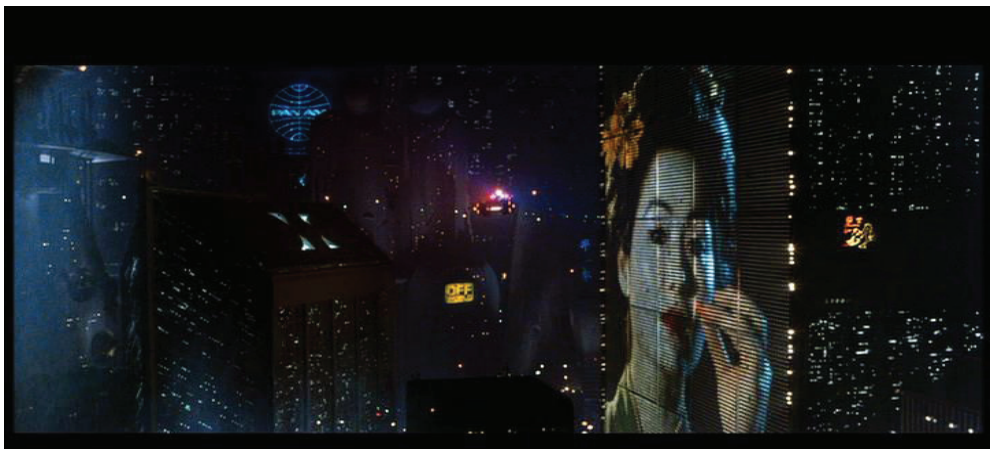

Mas "a mercadoria procura olhar-se a si mesma na face, ver a si própria no rosto" (BENJAMIN, 1994: 163): a maquilagem, disfarçando artificialmente a expressão individual, traz novamente a fisionomia impessoal da mercadoria, o sempre-igual, na imagem da mulher como artigo de massa.

da propaganda: a irrealidade. O novo mundo (new world) é fora do mundo (off world). Viver no seio da irrealidade, "fora do mundo", é a condenação de quem vive imerso no "novo mundo" das imagens fabricadas por essa indústria do simulacro.

O problema do controle dos meios de fabricação e inscrição das imagens na "superfície" é o problema do controle dos meios de organização da "experiência" e, por conseguinte, da "memória", pois não é outra a sua matéria. "Implantes”, diz Deckard para Rachael, com mais arrogância que empatia. E completa: "Não são suas memórias, mas as memórias de alguém, da sobrinha de Tyrell." As imagens fabricadas, que, uma vez captada pelo olho, se integram à teia da "memória", não têm sequer essa qualidade individual de "ser de alguém". Trazem a assinatura do corpo coletivo de produtores que as produziu, assim como a assinatura anônima das circunstâncias sociais de sua produção, das relações sociais de produção e circulação em que foram produzidas. Mais ainda: a "memória" que elas produzem não é apenas mediatamente, mas imediatamente coletiva, pois, fabricadas em escala de massa, produzem "experiências" em escala de massa. Benjamin chamou a atenção para essas dimensões do problema ao analisar o recuo, em todas as frentes, do valor de culto diante do valor de exposição dos "patrimônios da cultura” (BENJAMIN, 1987: 172-4) e ao 
indicar que o "autor consciente", que situa conscientemente sua produção dentro das relações de produção existentes, deve conceber suas obras não somente como produtos, mas como meios de produção, tendo em vista sua função organizadora (BENJAMIN, 1987: 131).

No tecido da "superfície” do mundo, cuja continuidade/configuração se constitui na sucessividade das aparências, as imagens fabricadas são como legendas que ensinam a "ler" o mundo, que estabelecem "princípios de legibilidade” do real. Na velocidade com que são percebidas, no tráfego, na televisão, no cinema e mesmo na internet (diante da qual os olhos educados pela repetibilidade e pela desconexão dos gestos na circulação da mercadoria, pelo tráfego, pelo ritmo da produção, pelo ritmo da inovação tecnológica e pelos outros mídias não se fixam demoradamente em nenhuma imagem, embora haja a possibilidade, tecnicamente disponível, de controle da exposição das imagens pelo "usuário”), essas imagens não convidam o observador à contemplação, não o abandonam às suas próprias associações. Como explica Benjamin, tratando do cinema, "quando o espectador percebe uma imagem, ela não é mais a mesma” ((BENJAMIN, 1994: 192). O observador é, assim, expropriado do poder de desarticular e rearticular as associações dadas pela "superfície" da imagem, de dissolver conexões e criar novas correspondências, pelo menos durante o ato da percepção. Esse poder se refugia agora na rememoração, mas esta mudou o seu significado.

Benjamin usa dois conceitos para captar essa modificação no significado da rememoração: memória involuntária e memória voluntária. É preciso recordar aqui os textos de Benjamin sobre Baudelaire: Paris do Segundo Império, Sobre alguns temas em Baudelaire, Parque Central.

Para Benjamin, a rememoração, em seu sentido originário, é da natureza da memória involuntária. A matéria da memória involuntária é a experiência, Erfahrung, explicitada como uma forma de percepção em que o evento é (perceptivamente) apropriado sem um plano atuante de composição, sendo enredado nas malhas formadas pela conjunção de conteúdos, não conscientemente mobilizados e arranjados, do passado individual e coletivo. Os conteúdos da memória involuntária não podem ser arregimentados, presentificados, por um esforço consciente do indivíduo. 
Em outras palavras, não estão disponíveis. Emergem no consciente independentemente de sua intervenção, desde que um estímulo externo os ative acidentalmente em razão de alguma afinidade intuitiva, sensorial. Emergem na forma de uma constelação, a aura, que, como uma atmosfera, envolve o objeto da percepção:

Se chamamos de aura as imagens que, sediadas na mémoire involuntaire, tendem a se agrupar em torno de um objeto de percepção, então esta aura corresponde à própria experiência que se cristaliza em um objeto de uso sob a forma de exercício. (BENJAMIN, 1994: 137)

Diferente é a natureza da memória voluntária. As análises de Benjamin sobre a modernidade, a mercadoria, a tecnologia da reprodução, a multidão, etc. revelam um ser humano que está todo inteiro concentrado na interceptação dos choques, que se tornaram a norma da vida cotidiana, exigindo uma permanente mobilização da consciência, como "razão de Estado” da sobrevivência física e psíquica do indivíduo. Essa mobilização permanente da consciência diminui as chances de os eventos se integrarem à experiência no sentido acima, pois sua recepção é atenuada, amortecida, por meio do controle consciente. A essa "experiência" Benjamin chama de vivência, Erlebnis, para diferenciá-la da autêntica experiência, Erfahrung. É a vivência a matéria da memória voluntária, que, diferente da outra, permite que seus conteúdos sejam mobilizados através de um esforço consciente de presentificação.

A força e a plenitude de significação com que as impressões passadas foram integradas à memória involuntária tornam o indivíduo agudamente sensível ao seu apelo. Iluminando as possibilidades de existência humana repelidas da realidade, as promessas de felicidade e as potencialidades traídas e proscritas pelo terror da socialização, seus conteúdos podem converter a rememoração em uma verdadeira redenção (no sentido benjaminiano), em um momento em que o presente se reconhece como visado por esse passado, coletivo e individual, que se the apresenta como sincrônico, exigindo a transformação do inconsumado em consumado. No entanto, a indisponibilidade dos conteúdos da memória involuntária não permite que 
se abra um verdadeiro espaço de liberdade, pois a rememoração está sujeita aos acasos que fazem emergir os conteúdos da memória involuntária. E, além disso, o indivíduo corre o risco de ser completamente possuído pelo fenômeno aurático, sendo escravizado pelo longe no lugar de libertar os momentos indestrutíveis aprisionados no passado para construir um mundo de liberdade.

A memória voluntária não está sujeita a essa limitação: seus conteúdos estão disponíveis. Todavia, como as impressões passadas foram recebidas de maneira atenuada, amortecida, o indivíduo pode desfiar os conteúdos da memória voluntária como as contas de um rosário, captandoos no tempo vazio e homogêneo do sempre-igual. Apreendendo o passado no fluxo do sempre-igual, a rememoração não é capaz de identificar os conteúdos verdadeiros presentes no passado, tanto no individual como no coletivo, em sua metamorfose à luz do presente. Há, assim, o risco de a rememoração não se efetivar como legítima re-memoração, como redenção, a qual exige arrancar as imagens de seu contexto para criar novas possibilidades de "legibilidade" e de ação, de configuração efetivadora do mundo. Não sendo capaz de re-memorar, de dissolver e criar novas conexões, novos contextos de "legibilidade", o ato de lembrar se torna uma reiteração obsessiva da estrutura de significado em que a "experiência" foi vivida, reiterando assim a ordem do consumado em vez de libertar o inconsumado. Essa incapacidade é particularmente danosa no contexto da tecnologia da fabricação e reprodução em massa das imagens, dado que essa tecnologia possibilita a manipulação da estrutura de significado da "experiência" pela manipulação da configuração do que aparece na "superfície”. A imagem é uma técnica de organização da "experiência" que constitui a matéria da "memória". Trazer a lembrança para perto na "rememoração" para irradiar uma reserva de significações intemporais é ignorar o processo social que a produziu e aquele em que ela sobrevive.

Na ficção de Blade Runner, para o replicante que recebe uma "memória" nos laboratórios de engenharia genética, o passado rememorado não é um passado individual. E, se ele não tem mais um passado individual, não pode querer salvar sua própria autenticidade como pessoa, mergulhando no longe temporal das recordações como quem tenta 
compreender o passado "como ele de fato foi”. De nada vale para Deckard rastrear sua história nas fotografias de "sua" família espalhadas sobre 0 piano como se elas fossem um reservatório do passado mais dignas de confiança que a própria "memória". As fotografias, como todas as outras réplicas de imagens, podem ser fabricadas ou manipuladas pela simples inscrição de uma legenda: fotografias da família de Deckard.

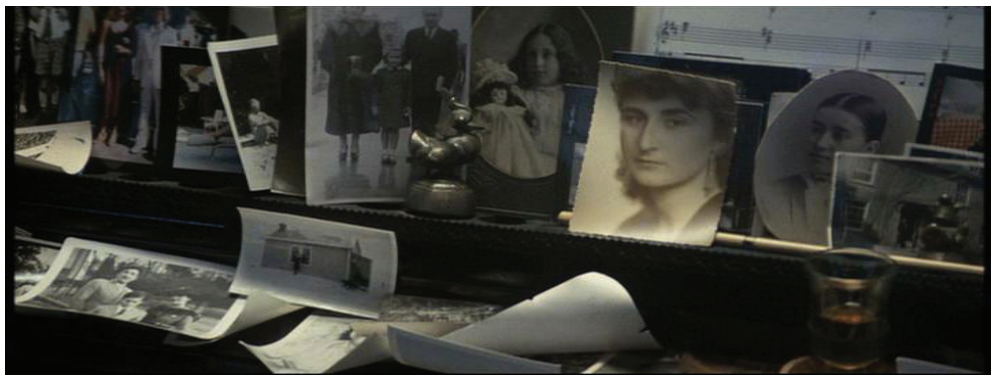

As fotografias familiares de Deckard. Mas Deckard não tem uma família. Como Rachael, ele tem um incept date. "O poder do simulacro está em toda parte" (Harvey, 1992: 281).

A situação-limite criada pela ficção é uma precaução contra falsas soluções. Todos nós estamos envolvidos no universo da fabricação e da replicação de imagens em escala de massa. O "poder do simulacro" é da ordem do sempre-igual e do sempre-novo que se refletem um no outro: apropria-se dos conteúdos do passado - que a aniquilação da tradição pelas tecnologias da reprodução e pela generalização da vivência como forma de percepção tornou disponíveis e usáveis - como dados mortos e, através da montagem, da manipulação das imagens na "superfície", encaserna o inconsumado do passado (felicidade, liberdade, poder de objetivação, revolução, etc.) na ordem do consumado (capital, mercadoria), refletindo o consumado no inconsumado e vice-versa, numa miragem que não se confessa em nenhum momento enquanto tal. Renovando o mundo para dentro, na ilusão transfiguradora de sua arte combinatória, o "poder do simulacro" impede o inconsumado de encontrar os meios de sua verdadeira realização pela destruição do consumado, as relações de produção vigentes. Nessa ordem de coisas, a rememoração não pode desempenhar um papel emancipatório se se limita a fazer o inventário dos 
conteúdos da "memória". A rememoração deve assumir positivamente o barbarismo desfigurador da alegoria contra o barbarismo transfigurador da indústria do simulacro, extraindo o passado de sua continuidade na "superfície", para revelar o seu contexto presente como montagem, afirmando o fluxo permanente da identidade e a revolução permanente da organização da "experiência" em um processo real de revolucionamento dos egos e das circunstâncias contra a eternização e a monumentalização do presente na "autêntica" identidade e no "autêntico" modelo de "experiência” dominantes.

\section{O olho na era de sua reprodutibilidade técnica}

O olho de Leon capturado pelo aparelho do teste. Já vimos essa cena. Ao lado da tela, um mostrador registra dilatações e contrações da íris. Assim destrinçado pelo aparelho, olho não é mais um organismo vivo, mas uma coleção, "cientificamente" organizada, de variáveis mensuráveis com precisão. O que é destruído nessa absorção do olho pelo aparelho não é apenas a autoridade do objeto, sua sacralidade, por assim dizer, mas sua integralidade orgânica. Nessa condição, dessacralizado e desintegrado, é que ele se torna plenamente disponível para ser reconfigurado pela intervenção tecnológica.

A destruição da integralidade orgânica dos objetos permeados pela tecnologia está ainda mais fortemente representada no filme pelo fato de os órgãos dos replicantes serem concebidos e produzidos isoladamente uns dos outros. É assim que, na tentativa de infiltrar-se no coração do aparelho produtivo que os fez, Roy e Leon se deparam com uma pequena oficina de olhos. Lá dentro um chinês já idoso, Chew, um genetic designer de olhos, trabalha cercado de aquários em que olhos bóiam em uma solução pastosa e clara. No detalhe da cena isolado na figura abaixo, Chew retira um olho de um recipiente para examiná-lo no microscópio.

Inquirido acerca de questões como "morfologia”, "vida útil”, "data de ativação" dos replicantes, ele responde: "Eu faço olhos... apenas olhos... desenhos genéticos... apenas olhos..." O conhecimento do conjunto de dados e técnicas envolvidos na produção dos replicantes está disperso no interior de uma rede altamente desagregada de relações entre empresas. A Tyrell 
Corporation domina a engenharia mais complexa da replicação: a engenharia do cérebro. Mas é, antes de tudo, uma montadora. Seu produto é uma "alegoria” genética viva. No entanto, a intenção não é alegórica, mas técnica e mercadológica.

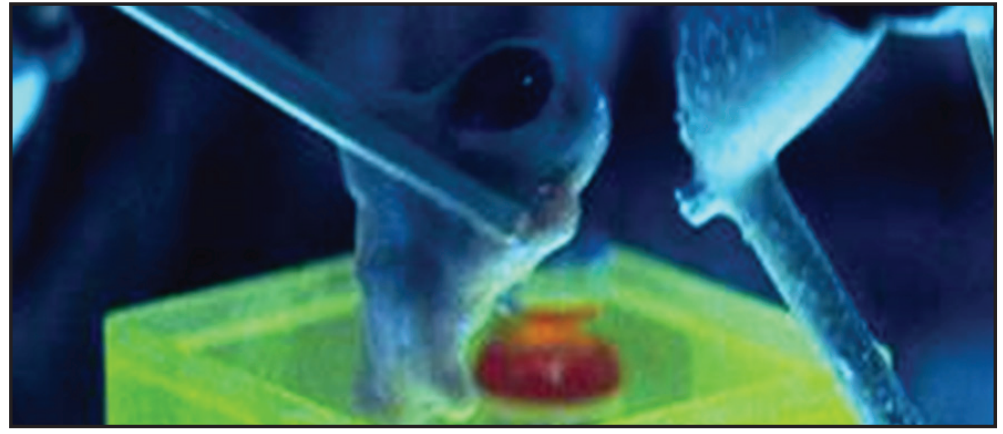

Os replicantes são produzidos como mercadorias de alto valor agregado e com o propósito específico de trabalhar em tarefas altamente especializadas e difíceis nas fronteiras da exploração espacial. No verbete de um suposto dicionário de 2012, a definição de replicante esboçada pelos roteiristas do filme inclui, como a definição de qualquer mercadoria, a discriminação de seu material e de seu valor de uso: "Criado em cultura de carne/pele. Transmutação/cópia genética seletiva. Capaz de pensamento auto-sustentável [self perpetuating]. Desenvolvido para o programa de emigração.” Deckard, para eximir-se da responsabilidade pela função que exerce, "retirar" ou "aposentar" (o verbo "retire" tem os dois significados e o filme joga com essa ambivalência) replicantes, se esconde atrás da confortadora ou cínica representação segundo a qual: "Replicantes são como qualquer máquina. Eles podem ser uma vantagem ou um azar. Se eles são uma vantagem, não é meu problema." Essa fala de Deckard exprime de maneira significativa o modo como os replicantes são encarados pelo aparelho produtivo que os fabrica.

O lema da Tyrell Corporation é "mais humano que um humano". Mas, para a Tyrell Corporation, o "humano" existe apenas enquanto uma mercadoria a ser consumida como força de trabalho, como fator tecnológico. O "mais humano" é a produção de um material humano o mais adequado possível para o cumprimento de uma determinada função. Roy é um "modelo 
de combate", Pris, um "modelo de prazer", e assim por diante. As linhas fisiológicas, "naturais", do material humano "replicado" são projetadas pelos engenheiros, evitando assim o desperdício que um organismo não destro para um certo padrão de desempenho poderia provocar. No lugar de selecionar e alocar as pessoas de acordo com a destreza que conseguem extrair de seus órgãos, a administração técnica passa a selecionar e programar geneticamente os órgãos para a destreza que deles será requerida. Como produto da ciência e da tecnologia desenvolvidas como poderes do capital, o "melhoramento" genético do ser humano não serve ao objetivo do livre e polimorfo desenvolvimento de suas qualidades, mas é a intensificação unilateral de uma qualidade completamente absorvida pela unidimensionalidade da relação social dominante.

Como fator tecnológico, o replicante deve ser uma variável controlada da racionalidade quantificadora capitalista, que visa a um retorno lucrativo na totalidade de seus investimentos adicionais. As qualidades desenvolvidas pelos replicantes para além da esfera estrita de sua utilidade para o capital apresentam-se como perniciosas para o livre e sereno curso da reprodução ampliada do mesmo. Por isso, os replicantes são programados para uma “vida útil” de apenas quatro anos. É uma medida de prevenção contra aquela "estranha obsessão" dos replicantes de não reconhecer "as experiências que você e eu aceitamos como verdadeiras” e de não se conformarem ao papel a eles designado pelo sistema.

Essa "alegoria” genética de ponta que é o replicante é montada sob a "lei" dos engenheiros-alegoristas. Genetic designer parece ser, de fato, um nome apropriado para esse "alegorista" genético. A arbitrariedade de sua "lei", servilmente subordinada aos ditames, orientados para o lucro, da lógica do capital, é que comanda a configuração do produto. Essa arbitrariedade é evidenciada pela autonomia com que a tecnologia manipula, em nome das exigências da subordinação do valor de uso ao valor de troca, das exigências da lucratividade, a morfologia e a longevidade ("vida útil” na linguagem da mercadoria) dos replicantes.

Essa arbitrariedade é ainda mais fortemente denunciada na forma caricatamente miniaturizada em que ela aparece no apartamento de J. F. Sebastian um dos designers da Tyrell Corporation. Lá encontramos um 
mundo de brinquedos e bonecos, um universo fantástico em que um anão narigudo aparece vestido como o Kaiser Wilhelm e um ursinho é travestido de Napoleão para repetirem um ritual. Com movimentos comicamente marciais, dirigem-se para Sebastian e estacam antes de o cumprimentarem: "Boa noite, Sebastian!"

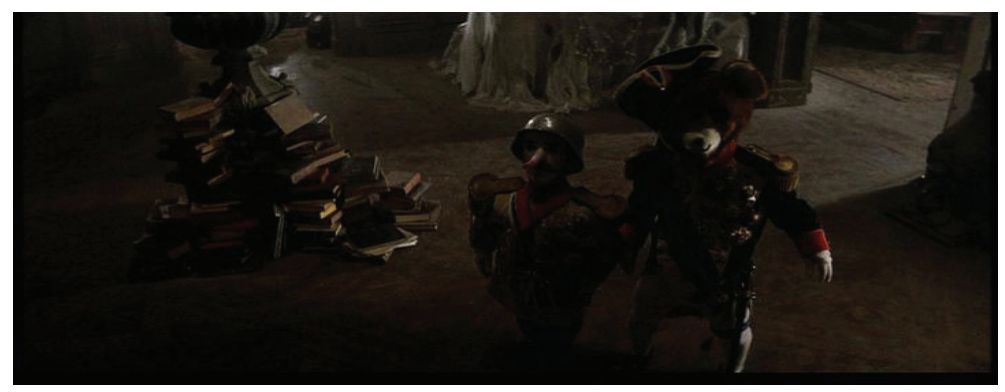

Sebastian constrói seu mundo de amigos ("Meus amigos são brinquedos. Eu os faço", explica para Pris) de modo tão soberano e voluntarista como qualquer criança egocêntrica e brinca com os artefatos culturais de maneira tão destrutiva e catártica quanto o cinema, que, nos grandes filmes históricos, reaviva Cleópatra, Napoleão, Shakespeare (apaixonado ou não) ou qualquer figura histórica (porque não passam de figuras) que se queira na era da "liquidação do valor tradicional do patrimônio cultural" (BENJAMIN, 1987: 169). O solitário Sebastian parece confortável com esse simulacro de sociabilidade que fabricou para si como um microcosmo no macrocosmo. Cansando-se dele, ele pode trocá-lo por outro. Mas esse mundo parece se vingar de Sebastian. Ele sofre de uma doença de envelhecimento precoce, assim como todas as coisas produzidas na ordem da mercadoria. $\mathrm{O}$ adulto infantilizado é o jovem envelhecido, assim como, na ordem da mercadoria, na qual nada aceita a estampa do definitivo, o sempre-novo é já o antigo.

Os replicantes são produtos desse mundo. Como "carcaças do tempo" que lutam contra o desperdício de suas vidas, é que eles se rebelam contra essa sociedade que "sobrepuja a vertigem do próprio aniquilamento na embriaguez da procriação" (BENJAMIN, 1982: 69), ou dito melhor, na embriaguez da replicação. É a extraordinária compressão do tempo de suas vidas que os 
enche de uma aflição destruidora. Querem parar os ponteiros do relógio, mas não podem. E "nada é pior do que uma coceira que você nunca pode coçar", lembra Leon. Como "alegorias” vivas, os replicantes não têm as mesmas possibilidades de recombinação da obra alegórica. Neles a arbitrariedade da "lei" que governa a configuração efetiva do mundo empírico escancara toda a sua perversidade. É a "lei" de um sistema que, orientado para a expansão e movido pela acumulação, transforma, já em sua fase "avançada", em medida do progresso técnico, a eficácia com que o desperdício pode ser gerado e dissipado em escala monumental.

Há por toda parte imagens de destruição criativa. Elas estão mais fortemente presentes, com efeito, na figura dos próprios replicantes, criados com poderes maravilhosos só para serem destruídos prematuramente e com certeza 'retirados' caso se envolvam de fato com seus próprios sentimentos e tentem desenvolver suas próprias capacidades à sua maneira. (Harvey, 1992: 280)

Tendo sua vida extraordinariamente comprimida, o replicante enxerga, através de sua vida, a sua morte, como se aquilo que as separa fossem apenas camadas de vidro, que, como na morte de Zhora, vão se quebrando, uma após a outra, até o desenlace final. Esse sentimento os impede de viver como todo mundo, os "little people", os homens comuns. É esse sentimento que os torna efetivamente "mais humano que um humano".

"Ou você é um policial ou você é gentinha [little people]", diz Bryan para Deckard. Na fala de Bryan, "little people” é a gente descartável, capitaliscamente supérflua, que, sem encontrar uma função "útil”, ainda circula pelas ruas de Los Angeles, vivendo do que é descartado, tolerada porque parece pouco ameaçadora ou talvez porque sua eliminação traria mais custos que benefícios para o sistema. Nas ruas, esse traço (little) é fisicamente representado por anões que aparecem catando lixo ou depredando carros e que se apresentam como um contraponto às criaturas titânicas fabricadas pela indústria da replicação, que ameaça lançar para sempre no inferno das subclasses não somente os "débeis", os "inválidos" e os refratários, mas todos os trabalhadores com poderes humanos comuns, pequenos (little) em comparação com os poderes dos replicantes. 
Para Roy, "little people" é a pessoa que esconde sua consciência atrás das regras do sistema. "Orgulhoso de si mesmo, homenzinho [little man]", pergunta para Deckard enquanto quebras dois dedos deste, um por Pris e outro por Zhora, ambas assassinadas por Deckard no cumprimento de sua "função". Para Roy, "little people" é pessoa que não enxerga nenhum objetivo de vida além da interminável perspectiva de meios que é a sua existência. "Little people" é um Chew que faz apenas olhos, apenas olhos, apenas olhos... e que é incapaz de pensar no mundo que é produzido com a contribuição fragmentária de seu trabalho. "Se você pudesse ver as coisas que vi com seus olhos", diz Roy para Chew, como uma pessoa que sabe que nenhum adiamento é mais possível e que por isso percebe tudo como irrepetível, como a última chance, como aquilo que irremediavelmente se perde no tempo. Para Roy, "little people" é o seu próprio Criador, Tyrell, que, como um deus, se sente onipotente no interior de seu santuário e que, como um homem comum, morre, com o crânio esmagado e os olhos perfurados pelas mãos potentes de sua criatura. A ciência responde por seus atos no tribunal profano das forças produtivas que liberou.

Roy não somente verbaliza sua raiva. Ele a celebra na experiência sacrificial da pureza destrutiva no homicídio. Mata Chew, Tyrell e Sebastian. Deckard é poupado. Enquanto persegue Deckard, a todo momento Roy evita concluir sua ação. Ele interrompe a ação fatal no meio de sua execução através da palavra, de frases muitas vezes rimadas, como em um teatro. Quando ele vê Deckard, tentando encontrar desesperadamente uma saída, em vez de cuidar de eliminá-lo logo, solta: "Four, five/ How to stay alive?" Instantes depois, com Deckard encurralado, ele prossegue a brincadeira: "Six, seven/ Go to hell or go to heaven?"

Quando Roy inicia sua caçada, algo de automático se manifesta em seus movimentos. Eles parecem imitar os movimentos de um atleta em um ginásio. É a repetição de seu treinamento. O nome completo de Roy é Roy Batty. O verbo "bat" designa o ato de bater. O substantivo "batter" designa o desportista que bate ou lança a bola no beisebol. "Batter in" é abater, quebrar, demolir. Ao interromper o gesto no meio da ação pela palavra, Roy parece querer romper com esse automatismo (bater, quebrar, demolir) inscrito em seu corpo e em seu próprio nome, do mesmo modo que luta contra a morte 
inevitável, tentando prolongar a vida mais um pouco por meio da dor (ele enfia uma peça de metal na mão). A interrupção do gesto pela palavra permite que o curso da ação ou da situação seja reconhecido como apenas uma das muitas possibilidades nela inscritas. Roy não pode reprogramar sua estrutura genética, não tem mais tempo para reprogramar a estrutura do mundo, mas ele até o último minuto é um rebelde: ele se rebela contra o próprio "eu" que os laboratórios da Tyrell Corporation tentaram implantar em sua cabeça como seu destino programado. No último momento, com Deckard prestes a cair do prédio, Roy não somente desiste de matá-lo como o salva da queda fatal. É quase exatamente nesse momento que Roy chega ao seu fim. Nos seus últimos instantes, ele fala com Deckard como quem fala de uma distância infinita: "Eu vi coisas que vocês pessoas não acreditariam... Naves de ataque em chamas ao largo de Orion... Eu vi raios-C cintilando na escuridão junto ao Portão de Tannhäuser... Todos esses momentos se perderão no tempo... como lágrimas na chuva... Hora de morrer." Roy não testemunha o seu último verso mudo - a pomba que escapa de suas mãos como a vida de seu corpo. Deckard pode continuar vivendo. "Mas quem é que vive?”, pergunta Gaff.

Na perseguição aos replicantes, Deckard é reeducado pela proximidade constante da morte. "Acorde. Hora de morrer", diz Leon para Deckard, que é salvo por Rachel. "Hora de morrer", diz Roy perseguindo Deckard. Essa experiência terrificante é que aproxima Deckard dos replicantes. A vida suspensa na morte quebra a continuidade da experiência vivida apenas como uma interminável busca de meios. Nessa suspensão, fluxo da vida imobilizado se reflete nos olhos da morte, como o fluxo da história na alegoria barroca:

A história em tudo aquilo que nela desde o início é prematuro, sofrido e malogrado, se exprime num rosto - não, numa caveira. (BENJAMIN, 1984:188)

Deckard foge com Rachel. Foge para onde? Para um novo mundo? Para fora do mundo? A fuga de Deckard e Rachael parece dialogar com o anúncio da Shimago-Dominguez Corporation. Deckard e Rachael querem "uma chance de começar de novo". Começar de novo é "a idéia regulativa do jogador", acusa Benjamin. É o tempo "daqueles a quem nunca é permitido concluir o que foi começado" (BENJAMIN, 1994: 129). "O final do filme”, escreve Harvey, "é 
uma cena de puro escapismo (tolerada, deve-se notar, pelas autoridades) que deixa como estão tanto o problema dos replicantes como as péssimas condições da frenética massa humana que habita as ruas criminosas de um mundo pósmoderno decrépito, desindustrializado e decadente" (HARVEY, 1992: 281). Não existe um "fora do mundo" onde possam refazer sua existência. O único mundo é este que é refletido por seus olhos. Não há saídas individuais. A única saída é realizar "o desejo mais profundo de Baudelaire": interromper o curso do mundo. Interromper o curso do mundo para reconhecer as possibilidades nele inscritas a fim de reordená-lo sob uma "nova lei", uma "lei" que seja o reconhecimento de que o mundo é uma montagem, que está sempre disponível para receber uma nova essência, para ser reconfigurado, e, mais ainda, o reconhecimento de que, em face dessa disponibilidade, qualquer autoridade diferente daquela dos "indivíduos livremente associados" é violência e terror. Mas o tempo de "vida útil" do mundo programado pelo capital é curto e o relógio não pára de correr. "Ataque, perigo e ritmo do político são técnicos não cavalheirescos” (BENJAMIN, 1982: 46).

\section{REFERÊNCIAS}

BENJAMIN, W. (1982) Rua de mão única. São Paulo: Brasiliense.

BENJAMIN, W. (1984). Origem do drama barroco alemão. São Paulo: Brasiliense.

BENJAMIN, W. (1987) Magia e técnica, arte e política: ensaios sobre literatura e história da cultura. São Paulo: Brasiliense.

BENJAMIN, W. (1994) Charles Baudelaire, um lírico no auge do capitalismo. São Paulo: Brasiliense.

HARVEY, D. (1992). A condição pós-moderna: uma pesquisa sobre as origens da mudança cultural. São Paulo: Loyola.

Agradeço a Alexandre Lucas Pires por apresentar-me aos roteiros do filme e por outras sugestões, em particular por chamar-me a atenção para certas expressões significativas, a exemplo de "little people" e "retire". 